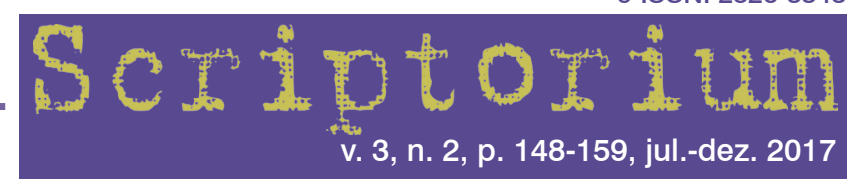

doi)" http://dx.doi.org/10.15448/2526-8848.2017.2.29416

\title{
Apontamentos sobre o exílio: ou a literatura como um reino
}

\author{
Notes on the exile: or literature as a kingdom
}

\author{
PAULA FÁBRIO* \\ Universidade de São Paulo (USP), São Paulo, SP, Brasil
}

\begin{abstract}
Resumo: Este estudo visa discutir o tema do exílio por meio da vida e obra de Sophia de Mello Breyner Andresen, Jorge de Sena e José Saramago, escritores portugueses do século XX. Também serão abordados, em diálogo, outros autores e pensadores marcados pelo degredo. Entretanto, pretendemos privilegiar o romance Ensaio sobre a cegueira, de Saramago, como objeto de análise, a fim de iluminar noções menos convencionais de exílio.
\end{abstract}

Palavras-chave: Exílio; Literatura portuguesa; Século XX.

\begin{abstract}
This work aims to analyze the theme of exile through Sophia de Mello Breyner Andresen's, Jorge de Sena's and José Saramago's works, Portuguese writers of the 20th century. Other writers and thinkers will also be discussed, in dialogue with exile as a concept. However, we intend to highlight the novel Ensaio sobre a cegueira by Saramago as object of analysis, in order to bring less conventional concepts of exile into light.
\end{abstract}

Keywords: Exile; Portuguese literature; 20th century.

\section{Introdução: conceitos e primeiras reflexões}

Nosso ponto de partida será explorar o conceito de exílio, antes de iniciar o debate sobre sua figuração literária; assim poderemos estabelecer distinções (e justaposições) entre exilados, refugiados, expatriados e emigrados.

Começaremos com Edward Said, crítico de origem palestina que viveu nos Esta- dos Unidos durante toda sua carreira acadêmica. Segundo Said, "o exílio tem origem na velha prática do banimento", enquanto os "refugiados são uma criação do Estado do século XX". O termo refugiado, de acordo com o autor, é carregado de conotação política, isto é, "sugere grandes rebanhos de gente inocente e desnorteada que precisa de ajuda internacional urgente"; por sua vez, o exilado "traz consigo um toque de solidão e espiritualidade" (SAID, 2003, p. 53).

\footnotetext{
* Mestre e doutoranda em Estudos Comparados de Literaturas de Língua Portuguesa, Universidade de São Paulo. Pesquisa “O deslocamento e a orfandade nas obras Livro, de José Luis Peixoto, e Os Malaquias, de Andrea Del Fuego".<paulafabrio2@yahoo.com.br>.
} 
Com relação aos expatriados, na opinião de Said, eles não recebem interdições, escolheram, de modo voluntário, viver em outro país. Já os emigrados "gozam de uma situação ambígua", pois "há uma possibilidade de escolha", embora muitas vezes essa escolha tenha sido a única possível, ou mesmo fruto de uma circunstância específica, caso dos colonos brancos na África, dos missionários e de conselheiros militares (SAID, 2003, p. 53). A título ilustrativo, gostaríamos de acrescentar à coluna dos emigrados, o fluxo de portugueses que se dirigiram à França durante a ditadura salazarista (PIRES, 2010), porquanto, suspeitamos, para esse contingente a emigração para aquele país seria a escolha possível.

Para o filósofo português Eduardo Lourenço, "[e]ntre exílio e expatriação há uma diferença de qualidade e de sentido relativa ao modo como se não tem já a pátria que se teve", em outras palavras, pode-se dizer que o "exilado está essencialmente na terra que deixou", assim "ninguém tem mais pátria que aquele que a perdeu e a vive como perdida". Desse modo, Lourenço argumenta que o expatriado, embora também possa se sentir exilado, "é um homem que largou amarras [...] e se assimila aos poucos a uma nova pátria". (LOURENÇO, 1984, p. 37-38).

Em um ensaio sobre o poeta português Jorge de Sena (também exilado, no Brasil e nos Estados Unidos), o professor Jorge Fazenda Lourenço resgata uma frase do escritor, por ocasião do Discurso da Guarda": "Portugal, como Camões, é a vida pelo mundo em pedaços repartida".

\footnotetext{
Discurso da Guarda, de 10 de junho de 1977, pode ser conferido em Rever Portugal: textos políticos e afins, ed. Mécia de Sena e Jorge Fazenda Lourenço, Obras Completas de Jorge de Sena, Lisboa: Guimarães, 2011.
}

Essa expressão poética, inspirada na obra do próprio Camões, expande a conceituação relativa às formas de se deixar um país (ou de um país deixar-se). Nesse mesmo ensaio, J. F. Lourenço utilizará a ideia de diáspora para ilustrar as nuances e os entrecruzamentos dos termos que se referem a dispersão. Comumente, segundo o ensaísta, empregamos diáspora para nos referir a "acontecimentos históricos muito dilatados no tempo", como a dispersão dos judeus. Com efeito, é preciso lembrar que o termo "diáspora" está repleto de "conotações religiosas, políticas, filosóficas, soteriológicas e escatológicas", e se justapõe, muitas vezes, ao conceito de exílio. Um exemplo notável dessa justaposição é a expulsão de Adão e Eva do paraíso, uma vez que houve banimento e deambulação (LOURENÇO, 2012, p. 109-111). O autor também chama nossa atenção sobre a designação de diáspora no vocabulário das ciências sociais, com destaque para os motivos econômicos que movem grupos e populações; nesse contexto, há justaposição com fluxo migratório.

Pelo que vimos até aqui, embora haja distinções entre exílio, emigração, expatriação e refúgio, as diferenças atenuam-se conforme aproximamos nosso olhar, por exemplo, dos fatores que geraram essa condição.

Entretanto, faz-se necessário observar que o exílio está associado ao nacionalismo (SAID, 2003), e este às construções culturais de Nação e identidade nacional (ANDERSEN, 2008). Dito isso, podemos concordar com Said quando ele trata do caráter provisório da pátria; para o crítico, o exilado tem a possibilidade de romper com essas construções e engendrar uma visão original sobre a vida e sobre os territórios. 
Vejamos esta passagem que torna mais clara essa formulação:

O exilado sabe que, num mundo secular e contingente, as pátrias são sempre provisórias. Fronteiras e barreiras, que nos fecham na segurança de um território familiar, também podem se tornar prisões e são, com frequência, defendidas para além da razão ou da necessidade. O exilado atravessa fronteiras, rompe barreiras do pensamento e da experiência. (SAID, 2003, p. 58).

Cabe apontar outro aspecto da noção, agora expandida, de exílio: a inexatidão das fronteiras, ou fronteiras fluidas. Diversos autores e intelectuais exilados não acreditavam em países; o poeta mexicano Mario Santiago, por exemplo, mencionado pelo escritor Roberto Bolaño durante um simpósio em Viena², somente respeitava "as fronteiras dos sonhos, as fronteiras trêmulas do amor e do desamor, as fronteiras da bravura e do medo, as fronteiras douradas da ética" (BOLAÑO).

Cumpre-se ponderar que essas reflexões nos trazem para o âmbito das fronteiras psicológicas, e por essa razão julgamos interessante pensar sobre outras formas de deslocamento além do físico. Uma delas seria a noção de nãopertencimento. Bolaño - ele mesmo um andarilho, que passou por vários países, como México, El Salvador, Espanha, França e Chile, este último seu país de nascença chegou a comentar, no referido simpósio:

\footnotetext{
2 O texto lido por Roberto Bolaño em Viena, Áustria, em abril de 2000, no Simpósio "Europa e América Latina: literatura, migração e identidade", foi incluído na coletânea de ensaios intitulada Entre paréntesis, publicada pela Anagrama em 2004. Posteriormente o texto foi traduzido para o português por Guilherme Freitas e publicado nos Cadernos de Leituras, sendo disponibilizado no site www.chaodafeira.com. A versão em português é referenciada em nossa bibliografia.
}

“ainda que não se saia da própria casa o exílio e o desterro se fazem presentes desde o primeiro momento". A propósito, para Bolaño, sua pátria é seu filho e sua biblioteca.

$\mathrm{Na}$ esteira desse pensamento, encontramos esta proposição de Jorge de Sena em uma entrevista de 1978: "Fui sempre um exilado, mesmo antes de sair de Portugal" (SENA apud LOURENÇO, 2012, p. 94). Todavia, segundo J. F. Lourenço (2012), Sena tinha o costume de alternar entre os termos "emigrante" e "exilado" ao falar de si próprio; na opinião do estudioso, essa maneira de se olhar e de se apresentar revelaria uma identidade plural. No campo intelectual, por exemplo, a pátria (qualquer que fosse) estaria a serviço de Jorge de Sena. A essa noção, Gagliardi refere-se como "intelectualismo sem fronteiras" (GAGLIARDI, 2014, p. 19).

Com base na conceituação vista e expandida, esboçamos nossas primeiras reflexões sobre o tema deste trabalho. A partir dessas explorações iniciais, gostaríamos de pensar a correlação entre a visão original proveniente do exílio (sugerida por Said) e a literatura como conhecimento do mundo, tendo na escrita e na leitura atos exilados por excelência (sugestão de Bolaño). Assim, dedicaremos a próxima seção a investigar, ainda que de modo sumário, a liberdade criativa dos escritores elencados neste trabalho.

\section{A liberdade do exílio e independência intelectual}

Valendo-nos novamente das ideias de Said - para quem "[o] exílio é a vida levada fora da ordem habitual", onde se contrapõem, a todo momento, dois ambientes diversos (pátria e degredo), e, 
por conseguinte, reduz-se o "julgamento ortodoxo" e eleva-se a "simpatia compreensiva" -, consideramos que o exílio apresenta condições ideais para o exercício da liberdade na criação da literatura (SAID, 2003, p.59), uma vez que o fazer literário é, por natureza, campo da alteridade.

Essa opinião é compartilhada no artigo do professor Caio Gagliardi:

[...] o sentimento de desenraizamento, que é fruto do exílio, conforma uma espécie de estado de emancipação, do qual também a ética estatal, advogada por Platão, foi banida, e no qual se abre um espaço de liberdade propício à escrita. (GAGLIARDI, 2014, p. 13, grifo do autor).

Note-se que essa condição não apenas encoraja, mas alimenta a obra de alguns autores. Jorge de Sena e Sophia de Mello Breyner Andresen, ambos exilados, são exemplos dessa dinâmica.

Elegemos alguns versos do poema "Em Creta, com o minotauro", de autoria de Jorge de Sena, e de "Pátria", de Andresen, para ilustrar nossos apontamentos. No primeiro caso, gostaríamos de sublinhar a independência de Sena com relação a pátria (qualquer pátria). No segundo, interessa-nos ressaltar a evocação da "pátria elementar".

Nascido em Portugal, de pais portugueses/e pai de brasileiros no Brasil/ serei talvez norte-americano quando lá estiver. / Coleccionarei nacionalidades como camisas se despem, / se usam e se deitam fora, com todo o respeito / necessário à roupa que se veste e que prestou serviço. / Eu sou eu mesmo a minha pátria. / A pátria de que escrevo é a língua em que por acaso de gerações nasci [...] (SENA, 2013, p. 516).
Por um país de pedra e vento duro / Por um país de luz perfeita e clara/ Pelo negro da terra e pelo branco do muro [...] Pedra rio vento casa/ Pranto dia canto alento/ Espaço raiz e água / Ó minha pátria e meu centro. (ANDRESEN, 2004, p. 146, espaçamento da autora).

O breve poema "Exílio", de Andresen, "Exilámos os deuses e fomos / Exilados da nossa inteireza" (2004, p. 239), traz - assim como "Pátria", com seu recurso aos elementos primordiais - a temática do retorno às origens da humanidade. Entretanto, no "Exílio" sobressai a busca pelo mito.

A propósito, Sena, no poema "Em Creta, com o minotauro", cujo excerto foi reproduzido acima, também lança mão do mito; a princípio temos a sugestão do título, e ao longo das estrofes verificamos a identificação do eu lírico com a condição de exilado do personagem mitológico. No mesmo poema, há a busca por uma Creta arquetípica, em alusão à civilização Minóica, anterior a Zeus: "Em Creta, com o Minotauro, / sem versos e sem vida, / sem pátrias e sem espírito, / sem nada, nem ninguém, / que não o dedo [do poeta] sujo [de tinta], / hei-de tomar em paz o meu café" (SENA, 2013, p.518). Igualmente interessante é a postura do eu lírico do poeta, contrária às construções culturais de pátria e espírito, revelando, com relação a este último constructo, sua oposição ao transcendente ${ }^{3}$.

O retorno às origens também pode ser identificado nas obras de Jorge de Sena e Sophia de Mello B. Andresen pela redução

\footnotetext{
As sugestões de o dedo do poeta estar sujo de tinta a alusão à Creta arquetípica, e do "espírito" como construção cultural são conjecturas procedentes das anotações em aula da disciplina Figurações do Exílio na Literatura Portuguesa do século XX.
} 
das palavras e das ideias ao mínimo denominador possível, ao gesto anterior ao gesto, da forma mais limpa a que se possa alcançar. Dizendo de outro modo, a tessitura da escrita de Sena e de Andresen tenderiam, à semelhança da experiência da filosofia fenomenológica, arriscamos dizer, a um núcleo comum. Examinemos estes versos do poema "Os trabalhos e os dias", referência a Hesíodo, que exemplificam essa busca: "À medida que escrevo, vou ficando espantado / com a convicção que a mínima coisa põe em não ser nada. / Na mínima coisa que sou, pôde a poesia ser hábito" (SENA, 2013, p. 88).

Cabe comentar, esta não seria, aparentemente, a forma literária escolhida por Saramago, cujo estilo apresenta-se repleto de frases e parágrafos extensos; no entanto, Saramago, por sua vez, opta por se aproximar do mito a partir da trama de seus romances: os personagens passam por ritos e por meio deles relacionam-se com os elementos primários, a água e o fogo, por exemplo. Atentaremos para essa e outras práticas saramaguianas na próxima seção, quando trataremos do romance Ensaio sobre a cegueira (1995).

Antes, porém, gostaríamos de acrescentar a observação de Vilma Arêas acerca da poesia de Andresen e que esclarece a noção de núcleo comum, porém interligada com a ideia de tempo. A estudiosa posiciona Andresen dentre aqueles que vêem a história como tragédia, porquanto no plano social sua obra se desdobra "num tempo anterior, 'clássico' na concepção lukacsiana, quando a aliança entre o ser e o mundo, entre as palavras e as coisas não estava quebrada" (ARÊAS, 2004, p. 22).

Essa quebra, por suposto ocorrida com o progressivo comprometimento do homem moderno com a razão, estende-se às predileções criativas de Saramago e Jorge de Sena.

A propósito, acreditamos que parte da decepção com as civilizações, de modo geral, nos três autores, Andresen, Saramago e Sena, deva-se também ao Estado Salazarista. Para explicitar essa percepção, citaremos alguns dados biográficos dos escritores.

Jorge de Sena quase seguiu para o campo do Tarrafal (prisão criada pelo Estado Novo) devido aos seus vários manifestos antisalazaristas; em determinado momento da vida, Sena muda-se para o Brasil, com o fito de se abrigar da ditadura em Portugal. Saramago, que também combateu o ditador em sua literatura e foi membro do Partido Comunista, viu-se somente na década de 1990 impelido a deixar seu país após um episódio de censura a seu livro $\mathrm{O}$ evangelho segundo Jesus $\mathrm{Cristo}^{4}$ (1991), escolhendo o autoexílio nas Ilhas Canárias, na Espanha. Andresen, por seu turno, "pertenceu à resistência ao regime salazarista, em 1969 foi candidata pela oposição e um dos membros fundadores da Comissão Nacional de Socorro aos Presos Políticos" (ARÊAS, 2004, p. 16); entretanto, sua obra figurou a imagem do exilado na própria terra, buscando "o exílio voluntário no belo, frequentemente feito em clave solitária, [...] nas paisagens marítimas da infância ou na Grécia Antiga" (VIEIRA, 2013, p. 109). Vale assinalar: “[e] scritores e artistas isolam-se amiúde de forma a potenciar a sua criatividade. E assim, o exílio e a poesia andam muitas vezes de mãos dadas" (VIEIRA, 2013, p. 106).

\footnotetext{
4 Esse romance foi vetado de uma lista de livros concorrentes ao Prêmio Aristeión pela Secretaria de Cultura de Portugal. Para ampliar o conhecimento sobre o exílio de José Saramago e sua residência na Ilha de Lanzarote, ver o documentário José e Pilar, de Miguel Gonçalves Mendes, 2010.
} 
Assim sendo, na obra de Andresen o exílio assemelha-se a um reino, onde o eu lírico se isola. Reino, nesse sentido, significaria um lugar elevado, um domínio preferencialmente anterior às civilizações.

Convém ressaltar outro traço comum à escrita dos três autores. Em nossa opinião opinião construída a partir da experiência de leitura em sala de aula durante disciplina do professor Caio Gagliardi -, todos eles possuem na estética um valor relevante e, ao mesmo tempo, não descuidam do engajamento social, daí o entrecruzamento interessante da temática do exílio com o recurso estético dos símbolos.

Contudo, como pudemos observar, o exílio de Saramago ocorreu tempos depois do fim da ditadura salazarista; e se deu como resposta ao cerceamento político-cultural imposto por seu país a sua literatura. Aliás, no Ensaio sobre a cegueira o autor deixa de abordar fatos históricos e desdobra seu enredo em territórios não denominados; nesse ponto preciso, entendemos que há uma emancipação de seus escritos com relação à pátria, ou ainda, houve um exílio (libertação?) em compasso ao seu exílio físico na Espanha.

É notório que Saramago manteve posições críticas ao catolicismo, com isso, acabou por obter antipatia da comunidade católica portuguesa e, por conseguinte, do governo daquele país. Muito além das polêmicas geradas por suas obras e declarações na mídia, a literatura de Saramago buscou reiteradamente a reflexão sobre a exploração do homem pelo capitalismo e, nesse tocante, caminhou de modo bastante próximo dos pensadores que colocaram em xeque a razão pura e o esclarecimento científico ${ }^{5}$.

5 Ver Dialética do esclarecimento: fragmentos filosóficos, de Adorno e Horkheimer, livro referenciado em nossa bibliografia.
Consideramos que Ensaio sobre a cegueira seja um dos livros de sua autoria mais contundentes sobre essa questão, posto que a cegueira branca surge como dado inexplicável no livro, inexplicável até mesmo pela ciência.

Agora, consideramos ter chegado em uma nova etapa de nosso estudo. Munidos com ideias gerais sobre o conceito de exílio e sua relação com a vida e a obra dos três autores portugueses examinados, iremos verificar, na próxima seção, como o exílio é figurado, em especial, no romance de Saramago, e como se dá seu emprego como artifício literário e recurso estético.

\section{Ensaio sobre a cegueira}

Importa lembrar, antes de iniciar o estudo sobre o romance de Saramago, que o livro não trata do exílio em sua acepção moderna, o exílio político de um intelectual. Embora o autor tenha se exilado na Espanha por motivos que poderíamos considerar políticos, seu livro envereda por outro caminho: o exílio do homem com relação ao mundo em que vive.

Em seus Cadernos de Lanzarote ${ }^{6}$ (1997 e 1999), diários do autor, Saramago faz inúmeras reflexões sobre os mais diversos assuntos, entretanto, objetivamos destacar aqui sua preocupação acerca dos rumos da humanidade e, sobretudo, da Europa. Nos Cadernos, irrompe sua inquietação e ceticismo com relação à Comunidade Europeia, uma vez que Saramago entende essa união como problemática, principalmente para países mais frágeis (política e economicamente) - caso de

\footnotetext{
Esses escritos de Saramago, em forma de diário, foram reunidos e publicados no Brasil em dois volumes, pela Ed. Companhia das Letras, com os títulos Cadernos de Lanzarote (1997) e Cadernos de Lanzarote II (1999). Neste trabalho nos referimos a essas edições.
} 
Portugal. Nesse âmbito, seu ceticismo provém, dentre outros fatores, do que ele considera falta de solidariedade entre os povos europeus (leia-se hegemonia de alguns países e setores econômicos); o autor também denuncia o sistema (capitalista neoliberal) "para o qual as pessoas não passam de produtores a todo o momento dispensáveis e de consumidores obrigados a consumir mais do que necessitam" (SARAMAGO, 1999, p. 65).

Grande parte desses questionamentos do autor, como pensador de sua sociedade, estão presentes em sua obra de ficção; no que tange à cegueira branca do Ensaio ${ }^{7}$, por exemplo, estamos falando da cegueira mais ampla, a cegueira de todos, que ocasiona a falta de solidariedade entre os indivíduos. Compreendemos essa cegueira como conotação da crítica ao culto da razão pura ${ }^{8}$, um dos obstáculos que impedem a todos de se tornarem (ou se reencontrarem?) realmente humanos.

Comecemos por discutir o simbolismo da expressão cegueira branca. Conjecturamos que Saramago se refira ao excesso de informações das sociedades modernas, o que possivelmente levou o homem à alienação. Dessa maneira, a cegueira figurada no livro seria diferente da atribuída à Idade Média, cegueira das trevas: sendo a cor branca a reunião de todas as cores, seu significado simbólico estaria mais ligado ao excesso, portanto teríamos uma doença dada pelo acúmulo imoderado de bens materiais, status, informações, ou seja, algo muito próximo das considerações do autor em seus diários.

Utilizaremos a forma reduzida Ensaio para o romance Ensaio sobre a cegueira, em alguns momentos.

8 Referência à radicalização do uso da razão, advogada pelo pensamento moderno, de Descartes a Comte, sobretudo.
A cegueira proposta por Saramago, acreditamos, também estaria atrelada à arrogância do saber e, ao mesmo tempo, à "coisificação" do ser humano. Esse tema, por sinal, aparece na obra saramaguiana antes mesmo do romance em voga. O conto "Embargo", do livro Objecto quase (1994), narra a história de um homem que se vê preso a seu carro, de modo inexplicável, assim como a cegueira surge no romance. As duas obras mostram, por meio do insólito, como o homem moderno vive à mercê dos produtos e das invenções de seu tempo. Isso reflete não apenas o apego aos bens materiais, mas também o domínio deste sobre os seres. No conto, por exemplo, é o carro que dirige o motorista em direção às bombas de gasolina:

De repente, o carro deu uma guinada e descaiu para a rua à direita, até parar numa fila de automóveis [...]. Manejou a alavanca das velocidades para meter a marcha atrás, mas a caixa não Ihe obedeceu. Tentou forçar, mas as engrenagens pareciam bloqueadas. (SARAMAGO, 1994, p. 37).

Já a cegueira, no Ensaio, provoca o fim da energia elétrica, dos meios de se armazenar alimentos e o término dos estoques de todo tipo de provisões; essas ocorrências geram um grau violento de disputa entre os personagens e demonstram o quanto o homem encontra-se desconectado da natureza e dos elementos primários.

Não obstante, Saramago enfatiza, por meio da cegueira como metáfora, em chave irônica, nosso hábito de não enxergar os próprios defeitos: "[...] teria ela própria de cegar também para compreender que uma pessoa se habitua a tudo, sobretudo se já deixou de ser pessoa [...]" (SARAMAGO, 1995, p. 218). 
Somente após todo um percurso iniciático (ou de reinício do ser), que envolve até mesmo uma descida às trevas, cujo extremo seria o episódio do fogofátuo na cave do supermercado (p. 297299), o núcleo de personagens protagonistas retorna aos seus lares e realiza ritos essenciais para sua humanização, como o gesto de dar banho em outra pessoa (banho no velho da venda preta, p. 270) - metáfora de solidariedade e amor; o banho das três mulheres na chuva (p. 266-267) e as histórias lidas sob a luz do fogo da candeia (p. 279) - imagens míticas que remetem à força integradora do feminino e do coletivo. Essas ações, de alguma forma, religam o humano ao fundamental, a um núcleo comum de convivência e solidariedade, ou, se quisermos, a um reino (nos moldes da poesia de Andresen).

A propósito da descida às trevas, há dois episódios semelhantes no livro, a descida da mulher do médico à cave do supermercado e, depois, quando ela volta ao local com o marido e encontra a cave repleta de cadáveres. Tanto o primeiro como o segundo episódio seriam preambulares à reconstrução (ou mesmo construção) da humanidade dos homens. O aguçamento dos sentidos e o uso da intuição são manifestos em ambas as passagens, e remontam a um período anterior as civilizações:

Empurrou a porta corrediça e recebeu quase simultaneamente duas poderosas impressões, primeira, a da escuridão profunda por onde teria de descer para chegar à cave, e logo, o cheiro inconfundível das coisas que são para comer, mesmo quando estiverem fechadas em recipientes a que chamamos herméticos. (SARAMAGO, 1995, p. 220).
Disse a mulher do médico, Há aqui um cheiro, Sempre cheira mal, disse o marido, Não é isso, é o outro cheiro, o da putrefacção, Algum cadáver que estará por aí, Não vejo nenhum, Então será impressão tua. O cão tornou a gemer. Que tem o cão, perguntou o médico, Está nervoso [...] (SARAMAGO, 1955, p. 297).

Além do enredo e das transformações das personagens, Saramago também utiliza a linguagem para aproximar seu texto do mito, da tradição oral, e assim afastá-lo do racional. Para isso, o autor se serve dos ditos populares como fórmula de conhecimento do mundo. Ao longo do livro, há inúmeros exemplos desse expediente; aqui selecionamos este que nos parece interessante justamente por "ensaiar" sobre os ditos e sua transformação ao longo do tempo:

Conheces o ditado, Qual ditado, O trabalho do velho é pouco, mas quem o despreza é louco, Esse ditado não é assim, Bem sei, onde eu disse velho, é menino, onde eu disse despreza, é desdenha, mas os ditados, se quiserem ir dizendo o mesmo por ser preciso continuar a dizê-lo, têm de adaptar-se aos tempos. (SARAMAGO, 1995, p. 269).

Conjecturamos que o retorno às origens, seja pela linguagem, seja pelos ritos contidos no enredo, esteja ligado à subjetividade do autor, se levarmos em conta que Saramago se retirou para Lanzarote em 1993 (lembremos: uma ilha, que remete a utopia e isolamento). Possivelmente as ideias contidas no romance e os planos de autoexílio foram gestados em tempos próximos. Assim, podemos inferir que, a partir da perspectiva do exílio, o espaço, como categoria narrativa, também se revela fundamental para pensar o romance de Saramago. 
A seguir, para dar continuidade a essa formulação, propomos esquadrinhar o modo como o espaço narra o exílio no Ensaio.

\section{Espaço restrito e libertário}

As personagens, no romance de Saramago, à medida que cegam, são banidas do convívio social da cidade e enviadas ao hospital (manicômio?), onde permanecem confinadas e submetidas a regras e restrições de toda ordem. Essa conformação é análoga ao exílio político moderno, no tocante ao banimento, e aos refugiados dispostos em campos isolados, se pensarmos em austeridade; entretanto, em um sentido mais radical, a quarentena do livro lembra o "exílio romano", no qual as pessoas eram proibidas de "cozinhar seus alimentos, entrar em qualquer habitação e mesmo se dirigir a outro indivíduo" (GAGLIARDI, 2014, p. 13).

Contudo, no ensaio, a situação dos "exilados" tende a piorar. Embora permaneçam agrupados, há pouquíssima coletividade. Com o passar do tempo, a desorganização entre os grupos de cegos aumenta, as brigas prevalecem e a área de convívio no hospital torna-se cada vez mais suja e insalubre. Para representar essa situação-limite, de bestialização humana, Saramago recorre ao uso progressivo de imagens escatológicas, a fim de tornar o espaço o mais sensorial possível para o leitor, conforme observamos nesta sequência:

[E] já estava nas últimas instâncias da urgência quando pôde enfim baixar as calças e agachar-se na retrete turca. O fedor asfixiava. Tinha a impressão de haver pisado numa pasta mole, os excrementos de alguém que não acertara com o buraco da retrete [...]. Sentiu-se infeliz, desgraçado a mais não poder, ali com as pernas arqueadas, amparando as calças que roçavam no chão nojento, cego, cego, cego [...]. Há muitas maneiras de tornar-se animal, pensou, esta é só a primeira delas. (SARAMAGO, 1995, p. 96-97).

Mais adiante na narrativa, após um terrível incêndio, os confinados sobreviventes "fogem" do hospital e passam a desfrutar de uma relativa liberdade, uma vez que todos cegaram na cidade (quiçá no mundo) e, assim, não serão presos novamente. No entanto, as personagens passam a deambular, à maneira dos povos banidos ou dispersos. E o que descobrem? Assim como o espaço fechado do hospital era hostil, as ruas agora são território de disputa, os comércios encontramse degradados, há lixo por toda parte e as condições de higiene inexistem, pois não há água encanada e nenhum tipo de organização social. Outra vez divisamos a deterioração do espaço e do corpo humano em paralelo com a degeneração moral do sujeito.

Há que se acrescentar ao caos social, o caos político:

Haverá um governo, disse o primeiro cego, Não creio, mas, no caso de o haver, será um governo de cegos a quererem governar cegos, isto é, o nada a pretender organizar o nada, Então não há futuro, disse o velho da venda preta, Não sei se haverá futuro, do que agora se trata é de saber como poderemos viver neste presente, Sem futuro, o presente não serve para nada [...] (SARAMAGO, 1995, p. 244).

Cabe sublinhar, o núcleo de protagonistas é dirigido, desde o isolamento no hospital até o fim da história, pela 
mulher do médico, aparentemente a única humana que não cegou. Responsável pela jornada dos demais, a personagem é ela própria uma construção metafórica, pois aquele que vê e repara (como na epígrafe) é aquele capaz de praticar a solidariedade e o desapego, duas virtudes da mulher do médico.

Com efeito, a reparação vem pelas mãos dessa personagem. É ela quem conduzirá seu núcleo de amigos de volta para casa. A propósito, o tópos do retorno é marcado como uma ascensão à ética, e o espaço da casa revela-se essencial como elemento narrativo agregador. Segundo o filósofo Gaston Bachelard:

[...] ficamos surpreendidos quando voltamos à velha casa, depois de décadas de odisseia [...], a casa natal inscreveu em nós a hierarquia das diversas funções de habitar. [...] Nela aprendemos hábitos de devaneio particular. (Bachelard, 1978, p. 207).

Lembremos que os ritos de purificação, no romance de Saramago, ocorrem todos dentro da casa; estamos falando do banho coletivo debaixo da chuva (varanda), do banho no velho da venda preta (casa de banho), das histórias "aquecidas" pelo fogo da candeia (sala). Todos esses ritos favorecem o devaneio e o (re)encontro do homem com sua humanidade. Dizendo de outro modo, as personagens começam, na casa, a construção de um reino. Mas antes de seguir por esse caminho, propomos uma pequena digressão.

Vejamos: a poeta Sophia de Mello B. Andresen recorre à imagem da ânfora dos primeiros gregos, em "Arte Poética I", como representação do retorno a um tempo no qual, como já comentamos, a aliança do ser com o universo não estava quebrada.
Com o recurso à metalinguagem, pois o texto pertence a uma série poética dedicada a pensar o processo de criação de seus poemas, a autora situa sua arte ao lado desse antigo vaso grego, objeto anterior à reprodutibilidade técnica - esta última contemplada no célebre ensaio de Walter Benjamin, cujo trecho a seguir nos servirá para amplificar essa clave de leitura.

Os gregos só conheciam dois processos técnicos para a reprodução de obras de arte: o molde e a cunhagem. As moedas e terracotas eram as únicas obras de arte por eles fabricadas em massa. Todas as demais eram únicas e tecnicamente irreprodutíveis. Por isso, precisavam ser únicas e construídas para a eternidade. (BENJAMIN, 1994, p. 175).

À pureza da ânfora para Andresen correspondem a chuva e o fogo no Ensaio, assim como o café com o Minotauro no poema de Jorge de Sena. Por isso "a beleza da ânfora de barro pálido é tão evidente, tão certa que não pode ser descrita"; e o café, livre de nacionalidade: "[a]penas o café, / aromático e bem forte, não da Arábia ou do Brasil, / da Fedecam, ou de Angola, ou parte alguma" (SENA, 2013, p. 518).

Dito isso, podemos retornar seja a casa, seja a uma cidade anterior as civilizações e, nesse espaço, entrar em contato com o puro, o anterior, o núcleo comum de todas as coisas, e também com o homem liberto da prisão do nacionalismo, isso porque a casa, o reino, independe de pátria. Atentemos, ainda, para a localização do eu lírico de Andresen: "[a] loja onde estou é como uma loja de Creta" (ANDRESEN, 2004, p.187, grifo nosso); ou de Jorge de Sena: "tomando café em Creta / com o Minotauro" (SENA, 2013, p.516, grifo nosso). Parece oportuno perguntar: onde se encontram os protagonistas do romance de 
Saramago quando o primeiro deles volta a enxergar? Eles estão na sala da casa (o reino) a ouvir a leitura de um livro (sob o lume), isto é, estão, em sentido figurado, dentro do livro. Além do apelo metalinguístico do gesto (nós também estamos lendo um livro, no caso o livro de Saramago e, quem sabe, aprenderemos algo sobre nós mesmos por meio dessa ação), de se aprender ouvindo, de se aprender com os outros, há uma imersão a um tempo anterior na história da humanidade, quando as pessoas se reuniam em volta da fogueira para ouvir histórias.

Dessa maneira, aproximamos ânfora, café, água e fogo, do objeto livro, ou de sua ideia anterior, as histórias. Esse movimento nos foi permitido por meio do espaço (loja, labirinto, Creta, casa, sala e livro) como categoria narrativa, e nos leva de volta à discussão entabulada inicialmente - o exílio como força ao mesmo tempo restritiva e criativa - porém, agora, presumimos ter estendido nossa proposição e chegado também a um núcleo comum de nossa pesquisa.

\section{Pequena conclusão ou pequeno atrevimento}

Julgamos que ambas as forças, restrição e criação, estejam ligadas com a solidão. Segundo Bachelard, "todos os espaços de nossas solidões passadas, os espaços em que sofremos a solidão, desfrutamos a solidão, desejamos a solidão, comprometemos a solidão, são em nós indeléveis" (Bachelard, 1978, p. 203), em outras palavras, para o filósofo e poeta francês, o espaço é um elemento privilegiado da memória. Por sua vez, os livros são constituídos de invenção e memória. Daí confirmamos a ideia de que o exílio, espaço de solidão, seja terreno fértil para a literatura. No entanto, o romance de Saramago nos faz lembrar (retorno às origens) o quanto estamos exilados de nós mesmos e que a leitura, embora solitária em tempos de alta reprodutibilidade técnica, ainda pode ser compartilhada e coletiva, porque os livros independem de territórios e as histórias são, por si mesmas, um reino.

\section{Referências}

ADORNO, Theodor W.; Horkheimer, Max. Dialética do esclarecimento: fragmentos filosóficos. Rio de Janeiro: Zahar, 1985.

ANDERSEN, Benedict. Comunidades imaginadas: reflexões sobre a origem e a difusão do nacionalismo. São Paulo: Companhia das Letras, 2008.

ANDRESEN, Sophia de Mello B. Poemas escoIhidos. São Paulo: Companhia das Letras, 2004.

ARÊAS, Vilma. "Sophia: clássica e anticlássica". In: ANDRESEN, S. M. B. Poemas escolhidos. São Paulo: Companhia das Letras, 2004.

BACHELARD, Gaston. A poética do espaço. São Paulo: Abril Cultural, 1978. (Os pensadores).

BOLAÑO, Roberto. Literatura e exílio. Caderno de Leituras. n. 22. Tradução Guilherme Freitas. Disponível em: <http://chaodafeira.com/cadernos/ literatura-e-exilio/>. Acesso em: 09 nov. 2016.

GAGLIARDI, Caio. O último exílio de Jorge de Sena: em Creta, com o Minotauro. Revista do CESP, Belo Horizonte, v. 34, n. 51, jan.-jun. 2014. Disponível em: <http://www.periodicos.letras. ufmg.br/index.php/cesp/article/view/6922>. Acesso em: 17 nov. 2016.

LOURENÇO, Eduardo. "As marcas do exílio no discurso de Rodrigues Miguéis". In: ALMEIDA, O. T. (Org.). José Rodrigues Miguéis: Lisbon in Manhattan. Providence: Gávea-Brown, 1984.

LOURENÇO, Jorge Fazenda. Matéria cúmplice: cinco aberturas e um prelúdio para Jorge de Sena. Lisboa: Babel, 2012.

PIRES, Rui Pena (Org.). Portugal: Atlas das migrações internacionais. Lisboa: Tinta da China, 2010.

SAID, Edward. "Reflexões sobre o exílio". In: . Reflexões sobre o exílio e outros ensaios. São Paulo: Companhia das Letras, 2003. 
SARAMAGO, José. Ensaio sobre a cegueira. São Paulo: Companhia das Letras, 1995.

Objecto quase. São Paulo: Companhia das Letras, 1994.

O evangelho segundo Jesus Cristo. São Paulo: Companhia das Letras, 1991.

SENA, Jorge de. Jorge de Sena - Obras completas. Poesia 1. Edição de Jorge Fazenda Lourenço. Lisboa: Babel, 2013.
VIEIRA, Cristina Costa. O exílio na vida e na poesia de Sophia de Mello Breyner. Revista Ubiletras. Beira, no 4, 2013. Disponível em: <http:// ubiletras.ubi.pt/wp-content/uploads/ubiletras04/ vieira-cristina-exilio-poesia-sophia.pdf $>$. Acesso em 19 de nov. 2016.

Recebido: 9 de julho de 2017. Aceite: 10 de outubro de 2017. 